\title{
Aromatic indolinic aminoxyls as antioxidants in cardiac sarcoplasmic reticulum lipid and protein oxidation ${ }^{\star}$
}

\author{
Dorota Kulawiak-Gałąska $^{1}{ }^{\bowtie}$, Michał Woźniak ${ }^{1}$ and Lucedio Greci ${ }^{2}$ \\ ${ }^{1}$ Department of Medical Chemistry, Medical University of Gdańsk, Poland; ${ }^{2}$ Dipartimento di \\ Scienze dei Materiali e della Terra, Università di Ancona, Italy
}

Received: 13 November, 2001; revised: 2 January, 2002; accepted: 10 January, 2002

Key words: indolinic aminoxyl, doxorubicin, protein and lipid oxidation

\begin{abstract}
The results presented demonstrate the influence of aromatic indolinic aminoxyls: 1,2-dihydro-2-ethyl-2-phenyl-3H-indole-3-phenylimino-1-oxyl (IA-C2) and 1,2-dihydro2-octadecyl-2-phenyl-3H-indole-3-phenylimino-1-oxyl (IA-C18) on oxidation of lipids and proteins of cardiac sarcoplasmic reticulum membranes.

We have used doxorubicin and t-butyl hydroperoxide as agents inducing oxidative stress in isolated rat cardiac sarcoplasmic reticulum membrane system. Carbonyl groups were measured as the end product of membrane protein oxidation, and thiobarbituric acid reactive substances were assessed as a marker of lipid peroxidation.

Inhibition of peroxidation of certain membrane components depends on the length of acyl chain. Aminoxyl IA-C2 inhibits the lipid peroxidation process while IA-C18 is an efficient protector against protein oxidation.
\end{abstract}

Lipid and protein oxidation due to free radical formation may be responsible for membrane damage upon doxorubicin (DOX) induced heart targeted free radical insult. Direct involvement of free radicals in the acute cardiotoxicity induced by doxorubicin is supported by the observation that compounds act- ing as free radical scavengers can significantly prevent the contractile impairment of the myocardium [1]. Univalent redox shuttle of the anthraquinone moiety of DOX can generate superoxide free radical [2]. It is commonly thought that the heart exposed to DOX shows a significant degree of membrane per-

\footnotetext{
${ }^{\star}$ Presented at the Polish Japanese Free Radical Forum, 2001.

${ }^{{ }_{T}}$ To whom correspondence should be addressed: Dorota Kulawiak-Gałąska, Department of Medical Chemistry, Medical University of Gdańsk, Dębinki 1, 80-210 Gdańsk, Poland; e-mail: dorkul@amedec.amg.gda.pl
}

Abbreviations: $\mathrm{Bu}^{\mathrm{t}} \mathrm{OOH}$, t-butyl hydroperoxide; DOX, doxorubicin; IA-C2, 1,2-dihydro-2-ethyl-2-phenyl-3H-indole-3-phenylimino-1-oxyl; IA-C18, 1,2-dihydro-2-octadecyl-2-phenyl-3H-indole-3-phenylimino-1oxyl; TBARs, thiobarbituric acid reactive substances. 
turbation arising from lipid peroxidation, which in turn largely contributes to cardiotoxic effects [3]. Careful inspection of hydroperoxides in blood plasma samples collected from the coronary sinus and femoral artery of nine cancer patients treated intravenously with doxorubicin, showed unexpectedly a paradoxical inhibition of cardiac lipid peroxidation [4]. These observations suggest that the exacerbation of the lipid peroxidation process observed in several models probably involves pre-existing Fe(II) complexes. In the presence of DOX and NADPH lipid peroxidation of an in vitro membrane system in the presence of DOX and NADPH is not observed if Fe(III) is not added [5]. Doxorubicin can be involved in oxidation of membrane lipids as well as proteins. It is still not clear whether these processes are independent or protein oxidation is a consequence of lipid peroxidation.

Taking this into account we decided to test if the oxidative stress induced by univalent reduction of doxorubicin can result in lipid and/or protein oxidation in isolated rat cardiac sarcoplasmic reticulum membrane.

Our experiments proved that the process of protein oxidation is independent from lipid oxidation induced by doxorubicin semiquinone radical, which is produced in one electron reduction reaction in the presence of NADPH. Besides DOX and NADPH, Fe(III) is needed for lipid peroxidation. Also Sugioka \& Nakano [5] demonstrated requirement for the ferric-ion-ADP-adriamycin complex initiating phospholipid peroxidation in an in vitro system. The recently reported requirement of Fe(III) for doxorubicin-mediated oxidative mutagenesis confirms the above mentioned necessity oxidative deterioration of non-protein biomolecules [6].

\section{MATERIALS AND METHODS}

Chemicals. Doxorubicin hydrochloride (Doxolem) was obtained from Lemery S.A. de
C.V. (Mexico). All other reagents were obtained from Sigma (St. Louis MO, U.S.A).

Subcellular fractionation of cardiac sarcoplasmic reticulum membrane (microsomes). Males Wistar rats (200-250 g) were used in the experiments. The animals were anaesthetised with diethyl ether and killed by decapitation. The hearts were removed quickly and placed in MSET buffer: $225 \mathrm{mM}$ mannitol, $75 \mathrm{mM}$ sucrose, $1 \mathrm{mM}$ EGTA, $10 \mathrm{mM}$ Tris/HCl, $\mathrm{pH}$ 7.4. The tissue was scissored and $20 \%$ homogenates were prepared. Each heart was homogenized in a Palmer homogenizer by 50 gentle up-and-down strokes. Nuclei and cell debris were removed by centrifugation at $450 \times \boldsymbol{g}$ for $2 \mathrm{~min}$. Supernatants were collected and centrifuged again at $10000 \times \boldsymbol{g}$ for $10 \mathrm{~min}$ in order to remove mitochondria. The postmitochondrial supernatant (cytosolic fraction containing sarcoplasmic reticulum membrane) was recentrifuged at $100000 \times \boldsymbol{g}$ for $1 \mathrm{~h}$. The pellet of sarcoplasmic reticulum membrane was suspended in $150 \mathrm{mM} \mathrm{KCl}, 10 \mathrm{mM}$ Tris $/ \mathrm{HCl}$ buffer, $\mathrm{pH}$ 7.4. The amount of protein was measured by biuret method [7]. A typical preparation yielded about $7 \mathrm{mg}$ of sarcoplasmic reticulum membrane per $1 \mathrm{~g}$ of heart tissue.

Assessment of thiobarbituric acid reactive substances (TBARs) in cardiac sarcoplasmic reticulum membranes exposed to t-butyl hydroperoxide. The membranes ( $2 \mathrm{mg}$ of protein suspended in $2 \mathrm{ml}$ of $50 \mathrm{mM}$ phosphate buffer, $\mathrm{pH}$ 7.4) were treated with 1 $\mathrm{mM} \mathrm{Bu}{ }^{\mathrm{t}} \mathrm{OOH}$ for $30 \mathrm{~min}$ at $37^{\circ} \mathrm{C}$. Aminoxyl IA-C2 or IA-C18 was added to the sample as ethanol solutions before addition of $\mathrm{Bu}^{t} \mathrm{OOH}$. The control samples were treated with $\mathrm{Bu}^{\mathrm{t}} \mathrm{OOH}$ and, instead of an aminoxyl an appropriate amount of ethanol was added. The extent TBARs production was measured according to Buege \& Aust [8] with $20 \mu \mathrm{M}$ in final concentration of butylated hydroxytoluene in order to prevent peroxidation of membrane lipids during thiobarbituric acid assay [9]. 
Oxidation of cardiac sarcoplasmic reticulum membrane protein after exposition to doxorubicin and indolinic aminoxyls. Sarcoplasmic reticulum membranes, $2 \mathrm{mg}$, were treated with $100 \mu \mathrm{M}$ doxorubicin and 1 $\mathrm{mM}$ NADPH in $1 \mathrm{ml}$ of $50 \mathrm{mM}$ phosphate buffer, $\mathrm{pH}$ 7.4, for $30 \mathrm{~min}$. Indolinic aminoxyls IA-C2 or IA-C18 were added at $25 \mu \mathrm{M}$ final concentration to the test tubes. A modified method of Levine et al. [10] for assessment of protein carbonyls was used. The entire process was performed in glass centrifuge tubes and $0.5 \mathrm{ml}$ of $20 \mathrm{mM}$ 2,4-dinitrophenyl hydrazine in $2 \mathrm{M} \mathrm{HCl}$ was added to $0.5 \mathrm{ml}$ of the membrane solution (1 mg protein). Blank reactions lacked only DNPH. Following $1 \mathrm{~h}$ incubation with continuous shaking the protein was precipitated by addition of $1 \mathrm{ml}$ of cold trichloroacetic acid $(20 \%, \mathrm{w} / \mathrm{v})$ and centrifuged at $3000 \times \boldsymbol{g}$ for $10 \mathrm{~min}$. The protein was then washed three times with ethanol/ethyl acetate $(1: 1, \mathrm{v} / \mathrm{v})$ and dissolved in $2 \mathrm{ml}$ of $6 \mu \mathrm{M}$ guanidine $\cdot \mathrm{HCl}, \mathrm{pH}$ 6.5. The amount of protein carbonyls was estimated using a molar absorption coefficient of 22000 at $360 \mathrm{~nm}$.

Synthesis of aminoxyls IA-C2 and IA-C18. Indolinic aminoxyl IA-C2 was synthesized as described by Berti et al. [11]. IA-C18 was also synthesized according to this method using $\mathrm{C}_{18} \mathrm{H}_{37} \mathrm{MgI}$ [12]. The alkyl iodide was obtained starting from the corresponding bromide by treatment with $\mathrm{NaI}$ ( 5 equivalents) in acetone. This procedure was applied because no reaction occurred with the commercial bromides used for the preparation of the Grignard reagent, even by activation of magnesium with $\mathrm{I}_{2}$ or diiodoethane. The aminoxyl was then purified by silica gel column chromatography, with cyclohexane/ethyl acetate $(9.5: 0.5, \mathrm{v} / \mathrm{v})$. IA-C18 was obtained in red semisolid viscous form; its crystallisation from hot ethanol proved unsuccessful. The identity and purity of the compounds were checked by thin-layer chromatography, by mass spectroscopy on a Carlo ERBA QMD 1000 spectrometer and by ESR spectroscopy on a Varian E-4 spectrometer.

\section{RESULTS}

Indolinic aminoxyl IA-C2 (structure presented on Scheme 1) added to sarcoplasmic reticulum membranes inhibited almost completely lipid peroxidation induced by $\mathrm{Bu}^{\mathrm{t}} \mathrm{OOH}$ as assessed by the amount of TBARs produced (Fig. 1a). Under the same conditions IA-C18 inhibited but slightly lipid peroxidation.

Figure $1 \mathrm{~b}$ demonstrates the effect of indolinic nitroxide antioxidants on sarcoplasmic reticulum membrane protein oxidation induced by doxorubicin in the presence of $\mathrm{NADPH}$. In this conditions the degree of protection exerted by IA-C2 and IA-C18 showed a pattern opposite to that observed in the lipid peroxidation system induced by $\mathrm{Bu}^{\mathrm{t}} \mathrm{OOH}$, namely IA-C2 was hardly effective while IA-C18 proved to be an extremely effective inhibitor of membrane protein oxidation.

Figure 2 illustrates typical ESR spectra of IA-C2 and IA-C18 in organic solvent (benzene) and in cardiac sarcoplasmic reticulum membranes under argon atmosphere. The presence of biological membranes changed the characteristics of the respective aminoxyl spectra, pointing to efficient membrane insertion of IA-C2, whereas almost complete broadening of IA-C18 indicated of strong immobilisation and probe spin-spin interaction in localized membrane domains.

\section{DISCUSSION}

Doxorubicin is a member of anthracycline antibiotics. Cardiotoxicity induced by DOX limits its clinical administration. Molecular mechanisms responsible for DOX cardiotoxicity have been widely discussed as unclear so far, despite many efforts to solve this intriguing problem. One of the discussed mechanisms is based on the ability of DOX to release free radicals in a cellular environment. Under such conditions DOX undergoes one electron reduction reaction with formation of doxorubicin semiquinone radical (DOX ${ }^{*}$ ) [13]. 
<smiles>CCC1(c2ccccc2)Nc2ccccc2C1[NH+]([O-])c1ccccc1</smiles>

IA-C2<smiles>[CH2]CCCC1(c2ccccc2)C(=[NH+]c2ccccc2)c2ccccc2N1[O-]</smiles>

Scheme 1. Structure of aromatic indolinic aminoxyls.

IA-C2, 1,2-dihydro-2-ethyl-2-phenyl$3 H$-indole-3-phenylimino-1-oxyl;IAC18, 1,2-dihydro-2-octadecyl-2- phenyl-3H-indole-3-phenylimino-1-oxyl.
The cardiac membrane proteins have been found as critical target of $\mathrm{DOX}^{\circ}$ attack. However, we are unable, in accordance with other authors [5, 14] to detect any accumulation of TBARs after exposition of membranes to DOX and NADPH as well established conditions for doxorubicin semiquinone radical formation.

In our experiments IA-C18 was able to anchor at membrane structures and protect membrane proteins against oxidation induced by doxorubicin. On the other hand, IA-C2 had

a

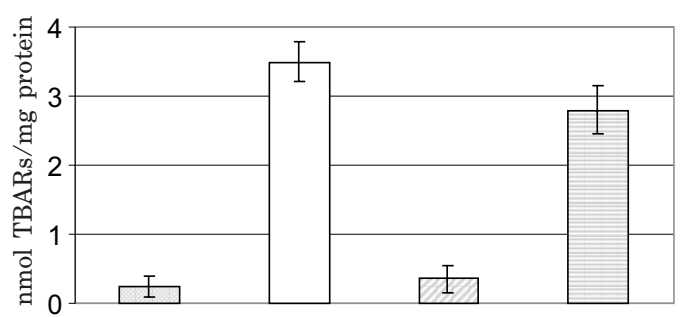

$\mathrm{b}$

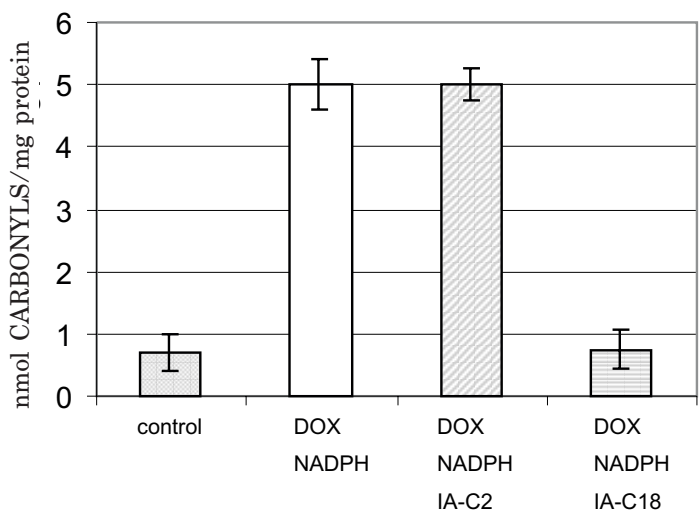

Figure 1. The effect of indolinic aminoxyls on lipid (1a) and protein (1b) oxidation in rat heart sarcoplasmic reticulum membrane.

a: $\mathrm{Bu}^{\mathrm{t} O O H}, 100 \mu \mathrm{M}$; IA-C2, $25 \mu \mathrm{M}$; IA-C18, $25 \mu \mathrm{M}$. b: DOX, $100 \mu \mathrm{M}$; NADPH, 1 mM; IA-C2, $25 \mu \mathrm{M}$; IA-C18, $25 \mu \mathrm{M}$. no effect on proteins but protected membrane lipids against peroxidation evoked by t-butyl hydroperoxide.

Selective oxidation of membrane proteins induced by DOX without involvement of iron is

A

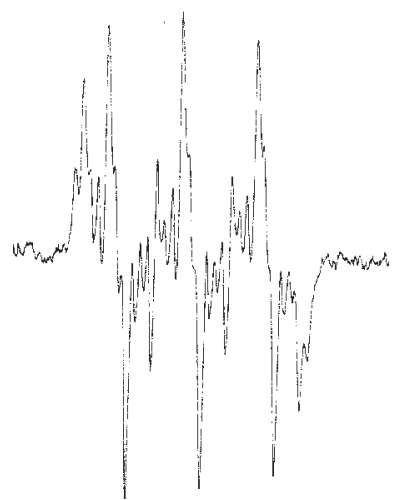

B

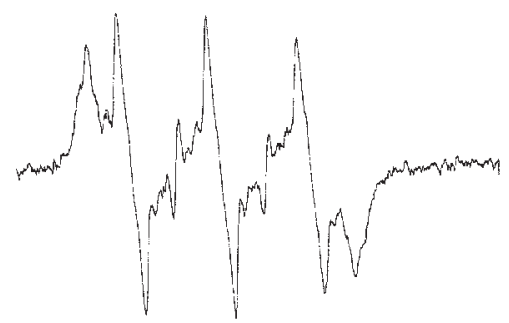

C

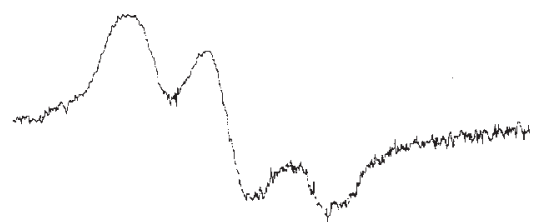

D

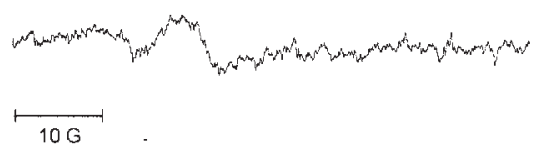

Figure 2. ESR spectra of aminoxyls.

A: IA-C2 in benzene; B: IA-C18 in benzene; C: IA-C2 in cardiac sarcoplasmic reticulum membrane; D: IA-C18 in cardiac sarcoplasmic reticulum membrane. 
one of the novelties of the present study. Another unexpected finding is the extreme efficacy of hydrophobic indolinic aminoxyl IA-C18 in protecting against oxidative damage. While insignificantly active in preventing lipid peroxidation, this aminoxyl displayed a strongly immobilized spectrum in sarcoplasmic reticulum membrane (Fig. 2). Partition studies with model phosphatidylcholine bilayer point to a surprising depth of penetration of anthracycline semiquinones into the membrane interior [15]. As doxorubicin semiquinone localizes preferentially to the depth of the 12th position of stearic acid in a membrane, it seems reasonable to assume that hydrophobic membrane protein domains are responsible for both-immobilization of indolinic free radicals localized scavengers and the subsequent efficient protection of sensitive residues inside the membrane domains. Aminoxyl TEMPOL is able to protect against the cardiotoxicity of doxorubicin only at a concentration as high as $2.5 \mathrm{mM}$ [16].

Aminoxyls can be divided into two distinct classes: the aliphatic one having nitroxide -NO function between two $\mathrm{sp}^{3}$ carbons like the tetra-methyl-piperidines (including TEMPOL) or pyroline, and those called aromatic aminoxyls, having the $-\mathrm{NO}^{\circ}$ group conjugated with a $\pi$ system, such as indolinic aminoxyls.
Due to free valence of the $-\mathrm{NO}^{\circ}$ groups both groups of aminoxyls, aliphatic (piperidine, pyroline) and aromatic ones, are able to couple with carbon-centred radicals $R^{\cdot}$ [17] (Scheme 2).

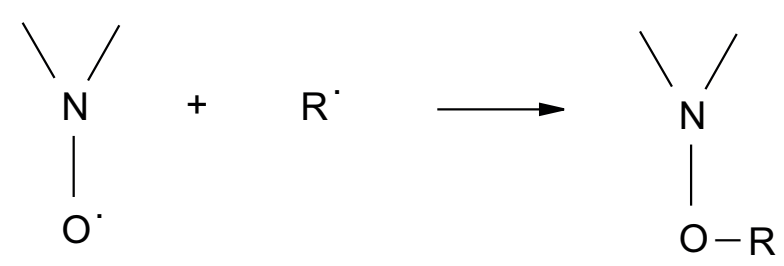

Scheme 2.

Aromatic aminoxyls having a conjugated benzene ring can react with virtually all kinds of oxygen centred radicals, namely $\mathrm{RO}^{\circ}$ and $\mathrm{ROO}^{\circ}$, forming diamagnetic compounds presented in Scheme 3.

Protein peroxyl radicals are well known intermediates of free radical dependent protein oxidation [18]. Due to high reactivity of aromatic aminoxyls with peroxyl species concentration as low as $25 \mu \mathrm{M}$ IA-C18 is sufficient to protect cardiac membrane proteins exposed on doxorubicin (Fig. 1).

Lipid and protein oxidation due to free radical formation is considered as one of the main factors responsible for disintegration of bio-

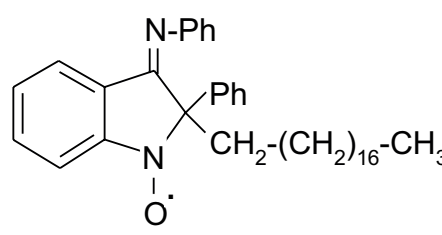

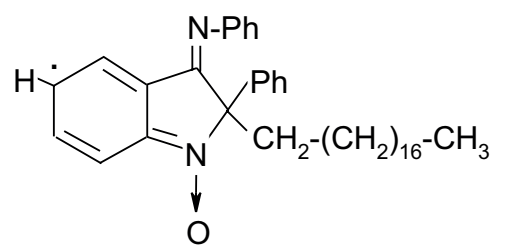<smiles>[Y]C(C)(C)[R]O[OH+]</smiles><smiles></smiles>

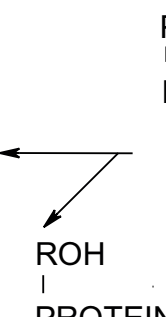

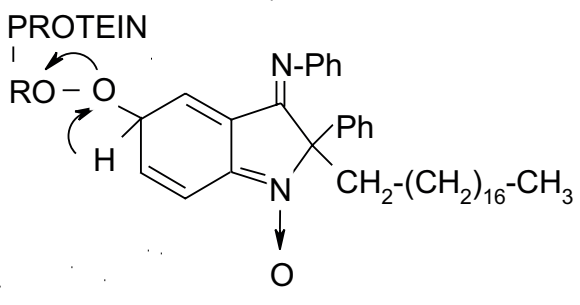

Scheme 3. 
logical membranes. The harm due to free radical overproduction (e.g. on application of doxorubicin) will be much more intense if the antioxidant status of the cell is rather poor, like in the cardiomyocyte as compared with the other cells [19].

It is generally accepted that, amongst the cellular components that can be damaged by free radicals, membrane lipids are most effectively protected by cellular antioxidants such as vitamin E [20]. The heart seems to be relatively deficient in this antioxidant as compared with other tissues [21]. Indolinic aminoxyl IA-C2 seems to be a good candidate for substituting of vitamin $\mathrm{E}$ in biological systems as it is a good antioxidant protecting membrane phospholipids (Fig. 1). On the other hand, so far there is little evidence that a hydrophobic or hydrophilic antioxidant can protect proteins [22]. The protective effect of IA-C18 on membrane proteins exposed to DOX and NADPH points to the possibility of applying a new strategy for rational design of an antioxidant molecule which would be an efficiently protect proteins against oxidative stress.

\section{R E F E R E N C E S}

1. Singal, P.K., Khaper, N., Palace, V. \& Kumar, D. (1998) The role of oxidative stress in the genesis of heart disease. Cardiovascular Res. 40, 426-432.

2. Doroshow, J.H. (1983) Effect of anthracycline antibiotics on oxygen radical formation in rat heart. Cancer Res. 43, 460-472.

3. Iliskovic, N. \& Singal, P.K. (1997) Lipid lowering: An important factor in preventing adriamycin-induced heart failure. Am. J. Pathol. 150, 727-734.

4. Minotti, G., Mancuso, C., Frustaci, A., Mordente, A., Santini, S.A., Calafiore, A.M., Liberi, G. \& Gentiloni, N. (1996) Paradoxical inhibition of cardiac lipid peroxidation in cancer patient treated with doxorubicin. J. Clin. Invest. 98, 650-661.
5. Sugioka, K. \& Nakano, M. (1982) Mechanism of phospholipid peroxidation induced by ferric ion-ADP-adriamycin-co-ordination complex. Biochim. Biophys. Acta 713, 333-343.

6. Kostoryz, E.L. \& Yourtee, D.M. (2001) Oxidative mutagenesis of doxorubicin-Fe(III) complex. Mutat. Res. 490, 131-139.

7. Futterman, S. \& Rollins, H.H. (1973) A simple biuret method for the estimation of protein in samples containing detergents. Anal. Biochem. 51, 443-447.

8. Buege, J.A. \& Aust, S.T. (1978) Microsomal lipid peroxidation. Meth. Enzymol. 52, 302310 .

9. Antosiewicz, J., Bertoli, E., Damiani, E., Greci, L., Popinigis, J., Przybylski, S., Tanfani, F. \& Woźniak, M. (1993) Indolinic and quinolinic aminoxyls as protectants against oxidative stress. Free Radical Biol. Med. 15, 203-208.

10. Levine, R.L., Garland, D., Oliver, C.N., Amici, A., Climent, I., Lenz, A.-G., Ahn, B.W., Shaltiel, S. \& Stadtman, E.R. (1990) Determination of carbonyl content in oxidatively modified proteins. Methods Enzymol. 186, 464478.

11. Berti, C., Colonna, M., Greci, L. \& Marchetti, L. (1975) Stable nitroxide radicals from phenyl-isatogen and arylimino derivatives with organometallic compound. Tetrahedron, 31, 1745-1753.

12. Antosiewicz, J., Damiani, E., Jassem, W., Woźniak, M., Orena, M. \& Greci, L. (1997) Influence of structure on the antioxidant activity of indolinic nitroxide radicals. Free Radical Biol. Med. 22, 249-255.

13. Bachur, N.R., Gordon, S.L, Gee, M.V. \& Kon, H. (1979) NADPH cytochrome P-450 reductase activation of quinone anticancer agents to free radicals. Proc. Natl. Acad. Sci. U.S.A. 76, 954-957. 
14. Demant, E.J. \& Jensen, P.K. (1983) Destruction of phospholipids and respiratory-chain activity in pig-heart submitochondrial particles induced by an adriamycin-iron complex. Eur. J. Biochem. 132, 551-556.

15. Alegria, A.E., Rodriguez, M.S. \& Hernandez, J. (1990) Semiquinones derived from anthraquinone-containing antitumor drugs can partition into phosphatidylcholine bilayers. Biochim. Biophys. Acta 1035, 51-55.

16. Monti, E., Cova, D., Guido, E., Morelli, R. \& Oliva, C. (1996) Protective effect of the nitroxide TEMPOL against the cardiotoxicity of adriamycin. Free Radical Biol. Med. 21, 463-470.

17. Chateauneuf, J., Lusztyk, J. \& Ingold, K.U. (1988) Absolute rate constants for the reactions of some carbon-centered radicals with 2,2,6,6-tetramethylpiperidine- $N$-oxyl. J. Org. Chem. 53, 1629-1632.

18. Dean, R.T., Fu, S., Stocker, R. \& Davies, M.J. (1997) Biochemistry and pathology of radi- cal-mediated protein oxidation. Biochem. J. 324, 1-18.

19. Kang, Y.J., Chen, Y. \& Epstein, P.N. (1996) Suppression of doxorubicin cardiotoxicity by overexpression of catalase in the heart of transgenic mice. J. Biol. Chem. 271, 12610-12616.

20. Burton, G. \& Ingold, K.U. (1986) Vitamin E: Application of the principles of physical organic chemistry to the exploration of its structure and function. Acc. Chem. Res. 19, 194-201.

21. Chen, Y., Saari, J.T. \& Kang, Y.J. (1994) Weak antioxidant defenses make the heart a target for damage in copper-deficient rats. Free Radical Biol. Med. 17, 529-536.

22. Neu il, J., Gebicki, J.M. \& Stocker, R. (1993) Radical-induced chain oxidation of proteins and its inhibition by chain-breaking antioxidant. Biochem. J. 293, 601-606. 